\title{
Variações sazonais de aspectos fisiológicos de espécies da Caatinga
}

\author{
Dilma M. de B. M. Trovão ${ }^{1}$, Pedro D. Fernandes ${ }^{2}$, Leonaldo A. de Andrade ${ }^{3}$ José Dantas Neto ${ }^{2}$
}

\begin{abstract}
RESUMO
No intuito de compreender as estratégias de sobrevivência utilizadas pelas espécies da Caatinga para se adaptarem às condições oferecidas pelo clima da região, avaliaram-se o potencial hídrico e a eficiencia quântica da fotossíntese obtida pela fluorescência das espécies: Myracrodruon urundeuva, Schinopsis brasiliensis, Amburana cearensis, Capparys cynophallophora, Anadenanthera colubrina var. cebil, Pseudobombax sp, Commiphora leptophloeos, Ziziphus joazeiro Bumelia sartorum, Caesalpinia ferrea, Maytenus rigida, considerando-se dois períodos de observação: estiagem (1) e chuvoso (2), para se verificar os possíveis identificadores de estresse. Com relação ao potencial hídrico verificaram-se diferenças estatísticas entre as duas estações, porém o fato que chamou a atenção reside nos altos níveis do potencial hídrico, mesmo no período de estiagem que, caracteristicamente, provocaria o estresse hídrico em função da ausência de água no solo. Os dados de fluorescência revelaram ótimos estados nos aparatos fotossintéticos, não indicando condição de estresse. Concluiu-se que as estratégias de sobrevivência dessas espécies são altamente eficientes e resultam de uma alta complexidade evolutiva.
\end{abstract}

Palavras-chave: potencial hídrico, eficiência quântica, semi-árido e recursos naturais

\section{Seazonal variations of physiological aspects of Caatinga species}

\begin{abstract}
With the purpose of understanding the survival strategies used by Caatinga species to face the weather conditions, the water potential and quantical photosynthetic efficiency of some species were studied. The data were obtained through the fluorescence of 11 species: Myracrodruon urundeuva, Schinopsis brasiliensis, Amburana cearensis, Capparys cynophallophora, Anadenanthera colubrine var. cebil, Pseudobombax sp., Commiphora leptophloeos, Ziziphus joazeiro, Bumelia sartorum, Caesalpinia ferrea, Maytenus rigidat. Two observation conditions of weather, the dry period and the wet one were studied, in which possible stress characteristics were verified. The study of the water potential presented statistical differences between the studied periods of climate. However, what drew attention were the high levels of water potential, even in the dry period, a situation in which commonly occurs water stress due to absence of soil water. The fluorescence data showed that the photosynthetic states were good with no apparent deficiency of water. In conclusion, it was verified that the survival strategies of these species are efficient and result from a highly complex evolution.
\end{abstract}

Key words: water potential, quantical efficiency, semi arid and natural resources

CCBS/UEPB. Departamento de Biologia. Av. das Baraúnas, 351. Campus Universitário. CEP 58.109-790. Campina Grande, PB. Fone: (83) 3315-3320; E-mail: dilmatrovao@oi.com.br

2 UAEAg/.UFCG, Av. Aprígio Veloso 882. Campus Universitário, CEP 58109-970, Campina Grande, PB. Fone: (83) 3310-1285. E-mail: pdantas@deag.ufcg.edu.br; zedantas@deag.ufcg.edu.br.

${ }^{3}$ Departamento de Fitotecnia/UFPB. Campus Universitário. Cidade Universitária. CEP 58.397-000, Areia, PB. Fone: (83) 3362-2300. E-mail: landrade@cca.ufpb.br 


\section{INTRODUÇÃO}

O estudo e a conservação da biodiversidade da Caatinga se constituem em um dos maiores desafios do conhecimento científico brasileiro, por diversos motivos, dentre os quais o fato da Caatinga se restringir ao território nacional, o que a torna uma região natural exclusivamente brasileira; outro é o fato de ser proporcionalmente a menos estudada e, também, a menos protegida, apenas $2 \%$ do seu território, sobretudo por continuar sendo vítima de um extenso processo de alteração e deterioração ambiental provocado pelo uso insustentável dos seus recursos (Leal et al., 2003); além desses se acrescenta, também, o fato de suas espécies apresentarem características fisiológicas que refletem adaptações complexas e peculiares às condições ambientais únicas.

Normalmente, na Região semi-árida brasileira a vegetação está condicionada ao déficit hídrico relacionado à seca, em decorrência da irregularidade das chuvas; analisando-se este fator, percebe-se que não é apenas a precipitação que provoca o déficit hídrico mas, também, a associação a outros fatores característicos da região, como altas temperaturas associadas à alta intensidade luminosa, que provocam uma demanda evaporativa alta e conseqüente dessecação do solo.

As plantas da Caatinga apresentam diversas adaptações fisiológicas às condições estressantes, sendo o estudo desses parâmetros de vital importância para o entendimento dos ecossistemas do semi-árido. O conhecimento dessas variáveis fisiológicas possibilita o entendimento de como as espécies vegetais conseguem se estabelecer neste ambiente, exteriorizando fenótipos condicionados pelo seu patrimônio genético, permitindo-lhes a permanência e, portanto, a sua evolução nos diversos ambientes, muitas vezes considerados inóspitos e inviáveis à sobrevivência.

Apesar disto, poucos são os trabalhos envolvendo o comportamento das espécies da Caatinga face às condições de estresse a que são continuamente submetidas, fazendo-se necessário pesquisas que envolvam os aspectos fisiológicos que permitam o entendimento de como essas plantas sobrevivem e suas estratégias evolutivas.

O potencial hídrico é um parâmetro que reflete o estado fisiológico dos vegetais, sua estabilidade ou completa eficiência no uso da água; alguns trabalhos avaliando este dado em plantas de Caatinga foram realizados por Nogueira et al. (1998) e Campos (1991). Níveis menos negativos de potencial hídrico refletem disponibilidade de água no solo ou adaptações bem sucedidas às condições estressantes. Conhecendo-se as variações no potencial hídrico de algumas das espécies vegetais que compõem a Caatinga, pode-se analisar as possíveis adaptações relacionadas a este fator e avaliar a sua influência em outros fatores fisiológicos.

A medição da fluorescência da clorofila pode ser usada para revelar informações sobre os estádios de desenvolvimento de plantas (Bacarin \& Mosquin 2002), para comparar genótipos (Portes \& Magalhães, 1993; Campostrini \& Maestri, 1998) e é usada, também, para investigar danos causados no aparato fotossintético, por diversas causas de estresses (Smille \& Not, 1982; Strant \& Oquist, 1988; Havaux et al., 1988; Torres Neto et al., 2002; El-Sheekh, 1993). Esta variável é uma significativa informação da eficiência fotoquímica do processo fotossintético (Torres Neto et al., 2002)

Desta forma, as aferições da fluorescência e do potencial hídrico de espécies da Caatinga, que constituem objetivos deste trabalho, podem contribuir para o entendimento do processo evolutivo dessas plantas sob condições adversas, permitindo caracterizar as diferenças fisiológicas nas duas estações características da Região Nordeste, o período chuvoso e o período de estiagem.

\section{MATERIAL E MÉTODOS}

O trabalho foi conduzido em duas etapas, uma no período de estiagem, em novembro de 2003 e outra no período chuvoso que, em 2004, foi anômalo e se iniciou em janeiro, quando foi realizada a segunda medição em função da alta disponibilidade de água e também à alta expansão vegetativa (principalmente das folhas) ocorrida no final do referido mês. As espécies estudadas se acham geograficamente inseridas na sub-bacia hidrográfica do Riacho de Bodocongó no Estado da Paraíba, nas Fazendas Bodopitá ( $7^{\circ} 22^{\prime} 27,8^{\prime}$ S, 3559'52,2” W) e Pocinhos ( $7^{\circ} 30^{\prime} 09,2^{\prime \prime}$ S e $35^{\circ} 57^{\prime} 39,9^{\prime \prime} \mathrm{W}$ ).

O clima da região é o semi-árido, a pluviosidade anual varia em torno de $450 \mathrm{~mm}$, com as chuvas se concentrando entre os meses de março e julho, sendo bastante incomuns nos outros meses do ano. A média anual da umidade relativa do ar está em torno de $50 \%$. Apresenta alto índice de radiação com temperatura média girando em torno de $25^{\circ} \mathrm{C}$. A classificação textural realizada em solos das Fazendas Bodopitá e Pocinhos, revelou a categoria franco-arenosa.

As espécies avaliadas foram Myracrodruon urundeuva Allem, Schinopsis brasiliensis Engl., Amburana cearensis (Allem.) A.C. Smith, Capparys cynophallophora L., Anadenanthera colubrina (Vell.) Brenan. var. cebil (Gris.) Alts., Pseudobombax sp, Commiphora leptophloeos (Mart.) J. B., Ziziphus joazeiro Mart. Bumelia sartorum, Caesalpinia ferrea Mart ex Tul, Maytenus rigida Mart., sendo amostrados três indivíduos de cada espécie, para avaliação do potencial hídrico e as medições de fluorescência. A escolha das espécies se deu em função da composição florística dos fragmentos analisados e os critérios de adaptação às medições realizadas, ou seja, a existência de órgãos nos dois períodos de coleta de dados (estiagem e chuvoso) que permitissem as análises necessárias (em virtude das variações climáticas, muitas das espécies característica da vegetação em estudo são caducifólias, o que descarta a medição da fluorescência, que foi um parâmetro aqui avaliado).

As aferições foram feitas sempre às $10 \mathrm{~h}$, em dias ensolarados, com nebulosidade parcial, para se observar a variação sazonal apenas dos dois parâmetros sem outras variáveis interferindo. Na análise estatística, adotou-se o delineamento inteiramente casualisado, com igual número de repetições ao se considerar, como tratamento, os períodos de observação e, como repetições, os indivíduos amostrados; enfim, utilizou-se o teste de Tukey, ao nível de 5\% de probabilidade, para comparação das médias. 
As medidas do potencial hídrico foram feitas com os ramos caulinares, em virtude de algumas das espécies apresentarem foliólulos de pequenas dimensões, não permitindo sua utilização; para manter o padrão, adotou-se o mesmo órgão para todas as plantas. Os ramos, de aproximadamente $10 \mathrm{~cm}$, eram retirados e colocados na câmara de pressão de Scholander, realizando-se a leitura após a primeira expulsão de líquido, através do corte.

As determinações da eficiência fotoquímica do fotossistema II foram realizadas em condições ambientais idênticas às do potencial hídrico, sendo colocados três leaf clip por planta (totalizando nove repetições) mantendo a área foliar coberta pelo tempo mínimo de 90 min (efeito Kautsky); após este período, realizaram-se as medições da emissão de fluorescência ao se empregar um detector de fluorescência do tipo PEA/Hansatech Instruments Co., quando foram determinados $F_{0}$ (fluorescência mínima ou inicial), Fv (incremento da fluorescência a partir de $\mathrm{F}_{0}$ até $\mathrm{Fm}$ ), Fm (fluorescência máxima) e a relação $\mathrm{Fv} / \mathrm{Fm}$, que permite a determinação do rendimento quântico da fase fotoquímica da fotossíntese.

\section{RESULTADOS E DISCUSSÃO}

\section{Potencial hídrico}

Os valores médios obtidos para o potencial hídrico caulinar $\left(\Psi_{\mathrm{c}}\right)$ nas espécies analisadas referentes aos dois períodos de observação (estiagem - 1 e chuvoso - 2) encontramse na Figura 1. A análise desses resultados permite afirmar que o potencial hídrico dessas espécies vegetais é bastante

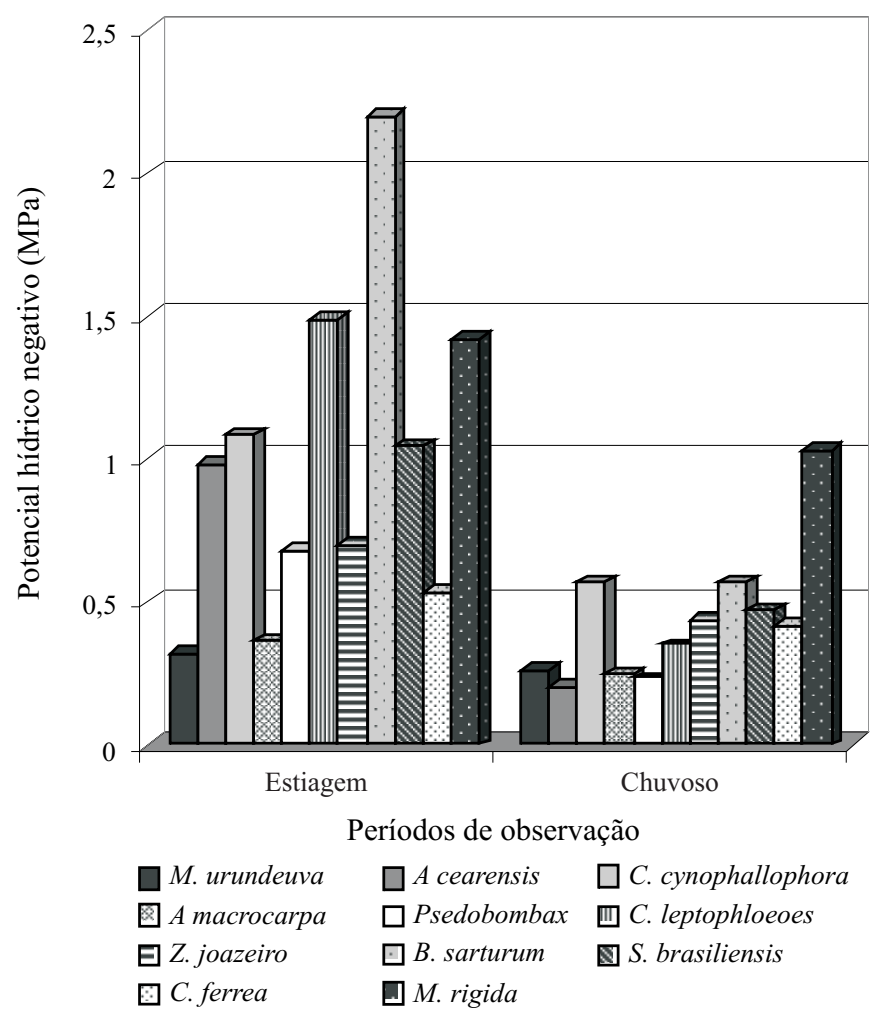

Figura 1. Potencial hídrico de espécies da Caatinga em dois períodos de observação (Estiagem e Chuvoso) sensível à variação da quantidade de água no solo; as espécies em estudo apresentaram perceptível aumento do potencial hídrico caulinar $\left(\Psi_{\mathrm{c}}\right)$ medido do período seco para o chuvoso, demonstrando a sensibilidade à variação do teor de água no solo resultante, evidentemente, das taxas de precipatação pluviométricas nos dois períodos, em que no inicial (novembro de 2003) o solo se apresentava bastante seco, característico do ambiente e resultante da baixa quantidade de chuvas nos meses anteriores; no final (janeiro de 2004) ocorreu um dos maiores índices pluviométricos já registrados na área de estudo nos últimos 100 anos, 367,6 mm, de acordo com o Laboratório de Sensoriamento Remoto e Recursos Hídricos do Estado da Paraíba; decorrendo disto, o suprimento da água no solo atingiu a capacidade de campo, disponibilizando para as plantas toda a água de que necessitavam.

As espécies aqui avaliadas têm suas características próprias de adaptação porém ante os dados apresentados, essas espécies se utilizam de artifícios para manter o estoque de água no interior da planta durante o período de deficiência hídrica que é, quase sempre, longo, como afirma Reis (1976) visto que, mesmo em condições de estresse, o potencial hídrico foi muito alto (pouco negativo) quando comparado com o potencial hídrico de espécies cultivadas em condições semelhantes.

Muitas medidas funcionais são desencadeadas pelas plantas para sobreviverem em condições de estresse hídrico ocasionado pela seca, entre as quais, modificações anatomomorfológicas que incluem aprofundamento do sistema radicular, diminuição no tamanho da folha, expansão caulinar e perda de folhas, dentre outras; porém, as mais interessantes são as modificações fisiológicas como a indução ao metabolismo ácido das crassuláceas e o ajuste osmótico.

Variações sazonais no potencial hídrico têm sido relatadas em plantas de regiões áridas; Goldstein et al. (1982) encontraram valores mínimos na época seca em plantas arbóreas de savana; San José (1977) observou valores iguais a -1,4 MPa para Curatela americana, também no período de seca.

A análise estatística das medições dos potenciais hídricos nos dois períodos (estiagem e chuvoso), revelou que as espécies Pseudobombax sp, Z. joazeiro, B. sarturum e S. brasiliensis apresentaram valores significativos $(\mathrm{p}<0,05)$ e as demais não significativos, o que, aparentemente, implica em que referidas espécies foram mais sensíveis a variação no nível de água no solo (Tabela 1).

$\mathrm{O}$ valor mínimo atingido para $\mathrm{Y}_{\mathrm{c}}$ no período de estiagem, foi de -0,31 MPa para a espécie $M$. urundeuva, e o máximo de -2,2 MPa para a espécie $B$. sarturum; já no período chuvoso, o menor índice também foi para $M$. urundeuva e o maior para $M$. rygida; em termos percentuais, as quedas registradas foram de $15,79 \%$ para $M$. urundeuva, $79,66 \%$ para $A$. cearensis, 47,69\% para C. cynophallophora, 31,81\% para $A$. colubrina, 65,51\% para Pseudobombax, 76,51\% para C. leptoplhoeos, 38,10\% para Z. joazeiro, 74,24\% para B. sarturum, $55,27 \%$ para $S$. brasiliensis, $21,87 \%$ para $C$. ferrea e $27,05 \%$ para $M$. rygida. É interessante frisar que as espécies $A$. cearensis e C. leptoplhoeos, mesmo com quedas tão altas, não apresentaram diferenças estatísticas entre os dois períodos.

Nogueira et al. (1998) realizaram trabalho sobre potencial hídrico das espécies Spondias tuberosa, Croton sincorensis, 
Tabela 1. Valores médios obtidos para os valores de potencial hídrico

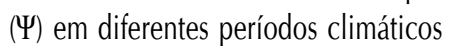

\begin{tabular}{lcc}
\hline \multicolumn{1}{c}{ Espécies } & \multicolumn{2}{c}{ Potencial Hídrico (MPa) } \\
\cline { 2 - 3 } Myracrodruon urundeuva & Estiagem & Chuvoso \\
Amburana cearensis & $0,32 \mathrm{~A}$ & $0,27 \mathrm{~A}$ \\
Capparis cynophallophora & $0,98 \mathrm{~A}$ & $0,20 \mathrm{~A}$ \\
Anadenanthera colubrina & $1,08 \mathrm{~A}$ & $0,57 \mathrm{~A}$ \\
Pseudobombax sp & $0,37 \mathrm{~A}$ & $0,25 \mathrm{~A}$ \\
Commiphora leptophloeoes & $0,67 \mathrm{~A}$ & $0,23 \mathrm{~B}$ \\
Ziziphus joazeiro & $1,49 \mathrm{~A}$ & $0,35 \mathrm{~A}$ \\
Bumelia sartorum & $0,70 \mathrm{~A}$ & $0,43 \mathrm{~B}$ \\
Schinopsis brasiliensis & $2,20 \mathrm{~A}$ & $0,57 \mathrm{~B}$ \\
Caesalpinia ferrea & $1,04 \mathrm{~A}$ & $0,46 \mathrm{~B}$ \\
Maytenus rígida & $0,53 \mathrm{~A}$ & $0,41 \mathrm{~A}$ \\
\hline Médias seguidas de letras iguais não são significativas a nível de 5\% pelo Teste de Tukey
\end{tabular}

Médias seguidas de letras iguais não são significativas a nível de $5 \%$ pelo Teste de Tukey

Mimosa hostilis, Z. joazeiro e Caesalpinia pyramidalis em dois períodos estacionais do ano de 1996 e constataram decréscimo no potencial de água no período de estiagem. Embora sejam espécies distintas das estudadas, esses dados demonstram compatibilidade com os valores apresentados neste estudo, uma vez que se trata de espécies características da mesma fisionomia vegetacional; os mesmos autores consideraram que, embora havendo diferenças significativas entre os potenciais hídricos nos dois períodos, elas não são tão distintas e isto se deve às suas adaptações já condicionadas evolutivamente, após várias secas sucessivas.

Outro autor que investigou o potencial hídrico de espécies da Caatinga foi Campos (1991), que também constatou variações sazonais neste parâmetro nas espécies Caesalpinia pyramidalis, Jatropha molissima, Aspidosperma pyrifolium e Mimosa hostilis.

\section{Eficiência quântica do fotossistema II (Eficiência fotossin- tética)}

Encontram-se representados na Figura 2, os valores médios da eficiência quântica fotoquímica $\left(E_{\mathrm{f}}\right)$ do fotossistema II, determinadas nas espécies $M$. urundeuva, A. cearensis, C. cynophallophora, A. colubrina, Pseudobombax sp, C. leptophloeoes, Z. joazeiro, B. sarturum, S. brasiliensis, C. ferrea, e $M$. rygida; esses valores correspondem aos períodos de estiagem e chuvoso.

Valores de 0,800 $\pm 0,05$ correspondem à máxima eficiência no uso de energia no processo fotoquímico (Björkman \& Demmig, 1987; Bolhàr-Nordenkampf et al., 1989; Torres Neto et al., 2002) e valores inferiores a 0,750 indicam situação de estresse e, portanto, redução do potencial fotossintético da planta (Maxwell \& Johnson, 2000; Araújo et al., 2004).

Embora se perceba, por meio da análise da Figura 2, tendência a valores inferiores no período de estiagem, estes não estão abaixo da faixa ótima da eficiência quântica, segundo Maxwell \& Johnson (2000) e, quando se analisa em termos percentuais, verifica-se que o decréscimo está na faixa de 3,7\%, sendo a diferença mais alta registrada para Commiphora leptophloeoes $(9,55 \%)$ e a mais baixa para Myracrodruon urundeuva (0,62\%).

Heckathorn et al. (1997) ao trabalharem com gramíneas sob

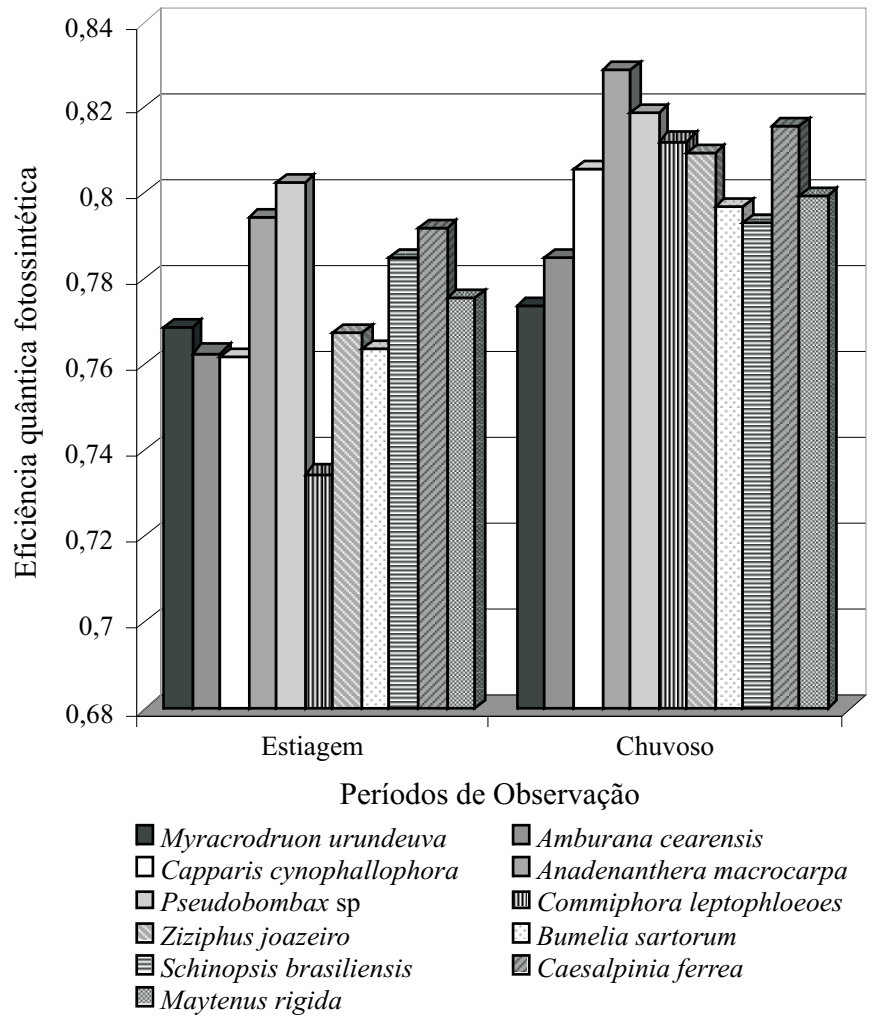

Figura 2. Eficiência quântica fotoquímica de espécies da Caatinga em dois períodos de observação (Estiagem e Chuvoso)

estresse, verificaram decréscimo de 4 a $8 \%$ comparado às plantas não estressadas; e Silva et al. (2001) também não encontraram prejuízo algum em relação às plantas estressadas e não estressadas, neste parâmetro; já para Krause \& Weis (1991), a análise da fluorescência, que evidencia a eficiência quântica máxima do fotossistema II, tem-se tornado fator muito importante nos estudos de estresse hídrico e Maxwell \& Johnson (2000) enfatizam que quando as plantas estiverem em condições não estressantes, seus valores se encontrarão entre 0,75 e 0,85; valores inferiores a estes indicarão estresse e redução da eficiência quântica máxima do fotossistema II.

As espécies Capparis cynophallophora, Anadenanthera colubrina, Bumelia sartorum e Caesalpinia ferrea apresentaram dados com diferenças estatísticas significativas para os dois períodos de observação, Tabela 2.

Embora sejam válidas as diferenças encontradas como registro de variações entre as duas estações, é conveniente a constatação de que nos dois períodos de observação havia a presença de folhas nas plantas e que algumas delas, como a Myracrodruon urundeuva, Anadenanthera colubrina, Pseudobombax sp. e Commiphora leptophloeos caracteristicamente em períodos longos de seca, se utilizam da abscisão foliar como forma de economizar água; sendo assim, provavelmente as plantas avaliadas dessas espécies ainda não estavam totalmente sob condições de estresse hídrico, e sem dúvida, essas similaridades nos resultados exprimem justamente a adequação ou adaptação dessas espécies às condições ambientais já relatadas, da área de estudo.

Queiroz et al. (2002), ao avaliarem a atividade fotossintética em plantas de Myracrodruon urundeuva, não encontraram 
Tabela 2. Valores médios obtidos para os valores de eficiência quântica da fotossíntese em diferentes períodos climáticos

\begin{tabular}{lcc}
\hline \multicolumn{1}{c}{ Espécies } & \multicolumn{2}{c}{ Eficiência quântica } \\
\cline { 2 - 3 } Myracrodruon urundeuva & Estiagem & Chuvoso \\
Amburana cearensis & $0,7690 \mathrm{~A}$ & $0,7738 \mathrm{~A}$ \\
Capparis cynophallophora & $0,7629 \mathrm{~A}$ & $0,7852 \mathrm{~A}$ \\
Anadenanthera colubrina & $0,7622 \mathrm{~B}$ & $0,8058 \mathrm{~A}$ \\
Pseudobombax sp & $0,7942 \mathrm{~B}$ & $0,8290 \mathrm{~A}$ \\
Commiphora leptophloeoes & $0,8026 \mathrm{~A}$ & $0,8186 \mathrm{~A}$ \\
Ziziphus joazeiro & $0,7347 \mathrm{~A}$ & $0,8123 \mathrm{~A}$ \\
Bumelia sartorum & $0,7676 \mathrm{~A}$ & $0,8092 \mathrm{~A}$ \\
Schinopsis brasiliensis & $0,7637 \mathrm{~B}$ & $0,7970 \mathrm{~A}$ \\
Caesalpinia ferrea & $0,7850 \mathrm{~A}$ & $0,7931 \mathrm{~A}$ \\
Maytenus rigida & $0,7922 \mathrm{~B}$ & $0,8156 \mathrm{~A}$ \\
\hline
\end{tabular}

Médias seguidas de letras iguais não são significativas a nível de 5\% pelo Teste de Tukey

diferenças significativas para este parâmetro nas plantas submetidas ao estresse hídrico, porém tal método avaliativo é proposto por diversos outros autores, como Krause \& Weis (1991) e Araújo et al. (2004), justamente para avaliar os danos causados ao aparato fotossintético sob este fator estressante.

\section{CONCLUSÕES}

1. Ocorreu decréscimo no potencial hídrico das plantas no período de estiagem.

2. Com relação à eficiência quântica do fotossistema II, encontraram-se diferenças significativas entre os dados dos dois períodos, sem evidência de danos no aparato fotossintético.

3. As espécies estudadas têm eficientes adaptações ao estresse hídrico.

\section{LITERATURA CITADA}

Araújo, R. A.; Siqueira, D. L.; Martinez, C. A.; Fernandes, A. R. Características Biométricas, índice SPAD-502 e emissão da fluorescência em porta-enxertos de citros. Revista Ceres, Viçosa, v.51, n.294, p.189-199, 2004.

Bacarin, M. A.; Mosquim, P. R. Cinética de emissão de fluorescência das clorofilas de dois genótipos de feijoeiro. Ciência Agrotecnica, Lavras, v.26, n.4, p.705-710. 2002.

Bjôrkman, O.; Demmig, B. Photon yeld of $\mathrm{O}_{2}$ evolution and chlorophyll fluorescence characteristics at $77 \mathrm{~K}$ among vascular plants of diverses origins. Planta, Berlin, v.170, p.489-504. 1987.

Bolhàr-Nordenkampf, H. R.; Long, S. P.; Baker, N. R.; Öquist, G.; Schreider, U.; Lechner E. G. Chlophyll fluorescence as a probe of the photosynthetic competence of leaves in the field: a review of current instrumentation. Functional Ecology, New York, v.3, p.497-514. 1989.

Campos, M. A. Aspectos morfo fisiológicos de plantas da Caatinga, durante períodos úmidos e de estresse hídrico. Recife: UFRPE. 1991. 129p. Dissertação Mestrado.

Campostrini, E.; Maestri, M. Photosynthetic potential of five genotypes of Coffea canephora Pierre. Revista Brasileira de Fisiologia Vegetal, Campinas, v.10, n.1, p.13-18, 1998.
El-Sheekh, M. M. Quenching of the variable fluorescence induced by zinc in the green alga Chlorella fusca. Revista Brasileira de Fisiologia Vegetal, Campinas, v.5, n.1, p.1-5, 1993.

Goldstein, G.; Sarmiento, G.; Meinzer, F. Um análisis de la economia hídrica em espécies de la sabana estacional y su interpretación ecologica y fisiológica. Acta Científica Venezoelana, Caracas, v.33, p.114, 1982.

Havaux, M.; Ernez, M. Lannoye, R. Correlation between heat tolerance and drought tolerance in cereals demonstrated by rapid chlorophyll fluorescence tests. Journal of Plant Physiology, München, v.133, p.555-560, 1988.

Heckathorn, S. A.; Delucia, E. H.; Zielinski, R. E. The contribution of drougth-related decreases in foliar nitrogen concentration to decreases in photosynthetic capacity during and after drought in prairie grasses. Physiology Plantarum, Copenhagen, v.101, p.173-182, 1997.

Krause, G. H.; Weiss, E. Chlorophyll fluorescence and photosynthesis. Annual Review of Plant Physiology and Plant Molecular Biology, New York, v.4, p.313-359, 1991.

Leal, I. R.; Tabarelli, M.; Silva, J. M. C. da. Ecologia e Conservação da Caatinga. Recife: UFPE, 2003. 804p.

Maxwell, K.; Johnson, G. Chlorophyll fluorescence-a practical guide. Journal of Experimental Botany, Oxford, v.51, p.659668, 2000.

Nogueira, R. J. M. C.; Melo Filho, P. A.; Santos, R. C. Curso diário do potencial hídrico foliar em cinco espécies lenhosas da Caatinga. Revista Ecossistema, Espírito Santo do Pinhal, SP, v.23, p.199-205, 1998.

Portes, T. A.; Magalhães, A. C. N. Análise comparativa de diferentes genótipos de feijão através da medição da fluorescência da clorofila a e o balanço de $\mathrm{O}_{2}$. Revista Brasileira de Fisiologia Vegetal, Campinas, v.5, n.1, p.17-23, 1993.

Queiroz, C. G. S.; Garcia, Q. S.; Lemos Filho, J. P. Atividade fotossintética e peroxidação de lipídios de membrana em plantas de aroeira do sertão sob estresse hídrico e após reidratação. Revista Brasileira de Fisiologia Vegetal, Campinas, v.14, n.1, 2002.

Reis, A. C. Clima da caatinga. Anais da Academia Brasileira de Ciências, São Paulo, v.48, p.325-335, 1976.

San José, J. J. Potencial hídrico e intercâmbio gaseoso de Curatella americana L. En la temporada seca de la sabana de Tractrypogon. Acta Científica Venezoelana, Caracas, v.23, p.373-379, 1977.

Silva, S.; Soares, A. M.; Oliveira, L. E. M.; Magalhães, P. C. Respostas fisiológicas de gramíneas promissoras para revegetação ciliar de reservatórios hidrelétricos submetidas à deficiência hídrica. Ciência Agrotécnica, Lavras, v.25, n.1, p.124-133, 2001.

Smille, R. M.; Nott, R. Salt tolerance in crop plants monitored by chlophyll fluorescence in vivo. Plant Physiology, Rockville, v.70, p.1049-1054, 1982.

Strant, M.; Öquist, G. Effects of frost hardening, dehardening and freezing stress on in vivo chlorophyll fluorescence of scots pine seedlings (Pynus sylvestris L.). Plant Cell Environment, Oxford, v.11, p.231-238, 1988.

Torres Neto, A.; Campostrini, E. Oliveira, J. G. De: Yamanishi, O. K. Portable chlorophyll meter for the quantification of photosynthetic pigments, nitrogen and the possible use for assessment of the photochemical process in Carica papaya L. Revista Brasileira de Fisiologia Vegetal, Campinas, v.14, n.3, p.203-210, 2002.

R. Bras. Eng. Agríc. Ambiental, v.11, n.3, p.307-311, 2007. 